\title{
High resolution 3-D modelling of cylinder shape bodies applied to ancient columns of a church
}

\author{
Giuseppe Casula $^{1}$, Francesco Cuccuru ${ }^{2}$, Maria Giovanna Bianchi ${ }^{1}$, Silvana Fais ${ }^{2,3}$, and Paola Ligas ${ }^{2}$ \\ ${ }^{1}$ Istituto Nazionale di Geofisica e Vulcanologia, Sezione di Bologna, Bologna, 40128, Italy \\ ${ }^{2}$ Department of Civil and Environmental Engineering and Architecture (DICAAR), \\ University of Cagliari, Cagliari, 09123, Italy \\ ${ }^{3}$ Consorzio Interuniversitario Nazionale per l'Ingegneria delle Georisorse, CiniGeo, Roma, 00186, Italy
}

Correspondence: Giuseppe Casula (giuseppe.casula@ingv.it)

Received: 11 June 2020 - Revised: 13 September 2020 - Accepted: 2 October 2020 - Published: 28 October 2020

\begin{abstract}
The use of Non-Destructive Testing (NDT) applied to construction materials allows to highlight and characterize their features, especially in the case of old buildings. The multi-technique high resolution 3D modelling described here is aimed to investigate the conservation state of the central column of a colonnade in the ancient church of Saints Lorenzo and Pancratio, dating to about the second half of the thirteenth century and located in the old town of Cagliari (Italy). This column was considered of interest because its longitudinal axis deviates from its ideal position and it appears the most deteriorated.

In this work we describe the integrated application of 3D diagnostic methods, i.e. Terrestrial Laser Scanner (TLS), close range photogrammetry (CRP) and ultrasonic tomography supported by petrographic investigations. They were used to improve the diagnostic process of the conservation state of the investigated column. The TLS technique was supported by CRP to obtain a natural colour texturized 3D model of the column. The geometrical anomaly maps derived from the data of the TLS-CRP survey show the presence of some anomalies worthy of attention. Starting from the $3 \mathrm{D}$ reconstruction with previous techniques we planned and implemented a 3D ultrasonic tomography. Ultrasonic tomography proved to be a successful tool in identifying internal defects, as well as the presence of voids and flaws within the materials through the analysis of the propagation of ultrasonic waves.

The integration of the three non-invasive techniques supported by petrographical analyses demonstrates its potential in reducing ambiguities since each technique brings its clue to the overall diagnostic process.
\end{abstract}

\section{Introduction}

For an adequate evaluation of the preservation state of the cultural heritage, in recent years the trend has been the use of independent multidisciplinary non-destructive diagnostics (Adamopoulos and Rinaudo, 2019). The diagnostics of the state of preservation of the architectural heritage is a topic that involves scientists, the Institutions, civil protection and also the economic aspect, because restorations and interventions for the maintenance of the monumental structures are also a source of economic revival (Montuori et al., 2014, 2016).

Non-destructive tests can be used to obtain the necessary qualitative and quantitative parameters to plan the recovery and preservation of a monumental structure. The multitechnique high resolution $3 \mathrm{D}$ modelling described here is aimed at investigating the state of conservation of a carbonate column in the ancient church of Saints Lorenzo and Pancratio in the Buoncammino district of the town of Cagliari (Italy) (Fig. 1). The church dates back to 1263, and shows a dedication to "Sanctum Brancasium [Pancratio]". It is a Romanesque building in calcareous ashlars of medium size with two aisles divided by arches on squat columns (Coroneo et al., 1993). One of these columns has been of prior interest and is the object of this study as its longitudinal axis deviates from its ideal position and presents many material detachments as seen from a preliminary visual inspection.

The integrated application of different Non-Destructive Testing (NDT) diagnostic methods is of paramount importance to locate damaged parts of the building material of artefacts of historical buildings and to plan their restoration (Bianchi et al., 2018; Casula et al., 2009; Fais et al., 2017 


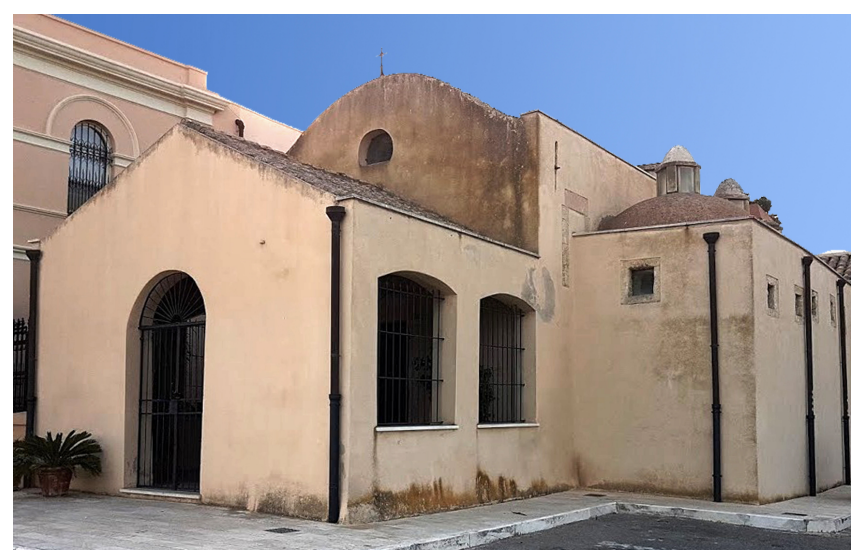

Figure 1. View of the old historic church of Saints Lorenzo and Pancratio in the old city centre of Cagliari.

2018). In this work we describe the integrated application of 3D diagnostic methods, namely Terrestrial Laser Scanner (TLS), close-range photogrammetry (CRP), and 3D ultrasonic tomography supported by petrographic investigations to produce data that can better visualize and detect defects in the shallow and inner parts of the investigated column and evaluate its state of conservation. A detailed petrographic study including thin section analysis and scanning electron microscopy (SEM) can greatly improve the interpretation of the non-invasive diagnostic techniques and especially the understanding of the behaviour of the ultrasonic signal propagation (Anselmetti and Eberli, 1997; Eberli et al., 2003; Fais et al., 2015, 2019a, b; Soete et al., 2015; Weger et al., 2004).

The non-invasive integrated approach is helpful in deciding whether any repair is needed, and how to choose the optimal repair techniques and prioritize interventions.

The TLS technique was supported by a CRP survey based on the structure from motion (SfM) methodology in order to obtain a natural colour texturized 3D model of the column. The geometrical anomaly maps derived from the data of the TLS-CRP survey show presence of anomalies worthy of attention. Starting from the 3D reconstruction by previous techniques a 3D ultrasonic tomography was planned and implemented in an optimal way on the column. The use of information based on the propagation of ultrasonic signals through the investigated materials represents one of the most common approaches for the elastic-mechanical characterization of the stone materials (Christaras et al., 2015; Cuccuru et al., 2014; Vasanelli et al., 2015; Wang and Li., 2015) and helps to detect defects and/or heterogeneities inside them. Velocity variations can be related with variations in the petrographical characteristics (especially texture) and/or with zones of different elastic-mechanical conditions. In fact, the ultrasonic analysis is based on the principle that the propagation of the ultrasonic signal depends on the density and the elastic constants of the materials. Therefore, any variation in the velocity of propagation of the ultrasonic signal indicates
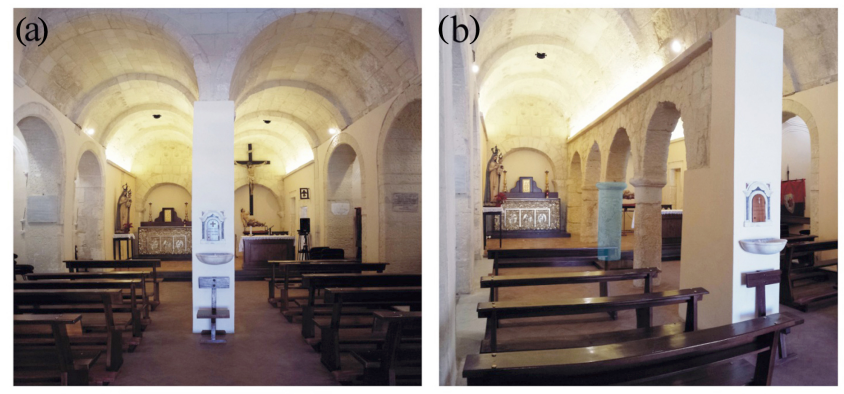

Figure 2. The interior of the church of Saints Lorenzo and Pancratio: (a) the two barrel vaulted naves; (b) the columns that support the round arches (the investigated column is highlighted in light blue).

non-uniformity of the material or presence of defects or discontinuities.

The combined use of geophysical and petrographical techniques represents a convincing method to identify the quality of the building stone materials in the shallow and inner parts of the investigated architectural structures (Casula et al., 2009; Fais and Casula, 2010; Fais et al., 2017, 2018, 2019a). Especially in complex situations, added value can be gained from the multitechnique datasets if the integration is appropriately performed and the intrinsic characteristics of the materials are known.

\section{Materials and Methods}

\subsection{Materials investigation}

The monument was built with local limestone ashlars and is characterized by two barrel vaulted naves (Fig. 2a) divided by round arches that rest on squat columns. The investigated column (Fig. 2b) is in the Doric order. It is built with the local Pietra Forte limestone, which was widely used in the past for its excellent geomechanical characteristics.

The first step of our methodology is an accurate microscopic examination of petrographic thin sections and a scanning electron microscope (SEM) analysis of the above carbonate materials to identify their textural characteristics and especially the nature and distribution of their porosity. Knowledge of these rock properties is fundamental to interpret the acoustic behaviour of the study carbonate rocks (Fais et al., 2019a) while providing the best criteria for understanding their alteration processes. The Pietra Forte represents the top facies of the upper Miocene Calcari di Cagliari Auct. (Gandolfi and Porcu, 1967; Cherchi, 1974). This lithology is characterized by well cemented and poorly porous biohermal and biostromal shelf limestones. According to the Dunham classification of carbonate sedimentary rocks (Dunham, 1962) Pietra Forte can be classified as boundstone, mainly made up of Lithotamnium algae and organogenic mollusc remains cemented by sparry calcite (Fig. 3a). Microscopically, 

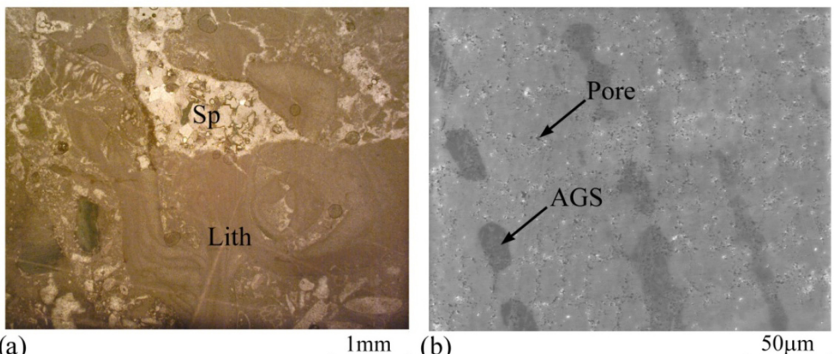

(a)

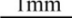

(b)

Figure 3. Textural characteristics of the Pietra Forte limestone: (a) lithotamnium algae (Lith) and sparry calcite cement (Sp), OM plane polarized light; (b) microporosity and algal growth structures (AGS), SEM image.

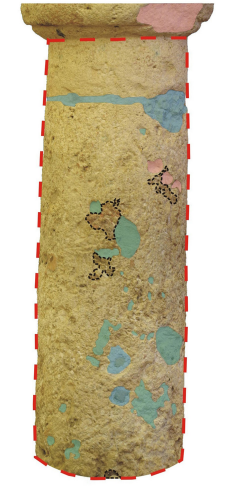

\section{Legend}

Degradation forms

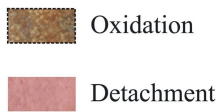

Restoration materials

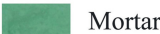

Mortar with stone fragments

Volume of the column shaft

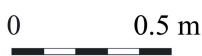

- - - investigated by CRP, TI and Ultrasonic Tomography

Figure 4. Shallow macroscopic characteristics of the investigated column.

Pietra Forte is a very compact carbonate with micropores less than $4 \mu \mathrm{m}$ in size, mainly related to the algal structures (Fig. 3b). The amount of micropores is about $1 \%-4 \%$. However, this lithotype is also characterized by secondary pores due to post-diagenetic dissolution processes that develop in karst cavities at the macroscale. The amount of macropores is relative because it depends on several factors, such as the degree of fracturing and water circulation which favours the karst phenomena.

At the preliminary macroscopic observation (Fig. 4) the studied column is characterized by shallow chemical alteration such as oxidation which colours the building material red, mainly at the base of the shaft. In the capital some material detachments occurred due to physical causes. The signs of previous restoration works are clearly visible in various sectors of the shaft (Fig. 4). These include mortar applications at times combined with stone fragments as filling materials.

The surface of the column is quite rough and irregular due to the natural macropores caused by the dissolution phenom- ena of calcium carbonate, especially in sectors with a higher concentration of fossils.

\subsection{D Modelling with Terrestrial Laser Scanner (TLS) and Close Range Photogrammetry (CRP)}

Generally speaking; TLS and CRP technologies are contactless proximal sensing NDT techniques useful to compute 3D models of buildings and architectural elements like wall, cylindrical shaped bodies like columns; pillars and other types of architectural artefacts. In this work we performed a synergistic application of the two techniques to carry out a very effective integration of the 3D model of the targeted column supplemented by the corresponding radiometric parameters such as TLS reflectance and natural colour texturing.

\subsubsection{Close Range Photogrammetry (CRP)}

CRP is a technique derived from computer graphics, which starting from a discrete number of $2 \mathrm{D}$ colour pictures can reconstruct the 3D structure of a target surface or object (Westoby et al., 2012; Blistan et al., 2020). The final results of the application of CRP are 3D models based on unified point clouds similar to the ones produced by TLS. CRP is also used to create high resolution digital surface models or models of complex geometry objects using single lens commercial uncalibrated Reflex digital cameras or sometimes smartphone cameras (Bianchi et al., 2018; Fais et al., 2018, 2019a). As for the TLS, for every point cloud generated with CRP the position is measured in an arbitrary reference system and the natural colours of the pixels are measured and expressed in general with a Red Green Blue (RGB) colour scale.

In this study the photogrammetric survey was carried out using a Nikon D-5300 Single-lens Reflex digital camera mounted on a tripod (Fig. 5a). A set of about 50 high quality $2 \mathrm{D}$ images was acquired evenly spaced all around the study column with a good level of exposition and successive images were acquired with an overlap of at least $30 \%$. Images are first visually inspected and processed with Agisoft Metashape ${ }^{\circledR}$ software. After a fine registration procedure of the images a unified point cloud is generated using the algorithm of the structure from motion (SfM) photogrammetry and formatted as input for the JRC 3D Reconstructor ${ }^{\circledR}$ software by Gexcel, which is used for cloud processing and is applied in the following stage of the processing.

During the process of generation of the unified aggregated high density point cloud, CRP data processing was performed with the Agisoft Metashape ${ }^{\circledR}$ facility starting from the addition of acquired photos, matching points and an accurate selection of image pairs to be followed respectively by the generation first of a sparse and finally of a high density cloud. At this stage we chose the high accuracy and preselection of generic pairs options while the depth of filtering option was settled as aggressive and the quality parameter as 

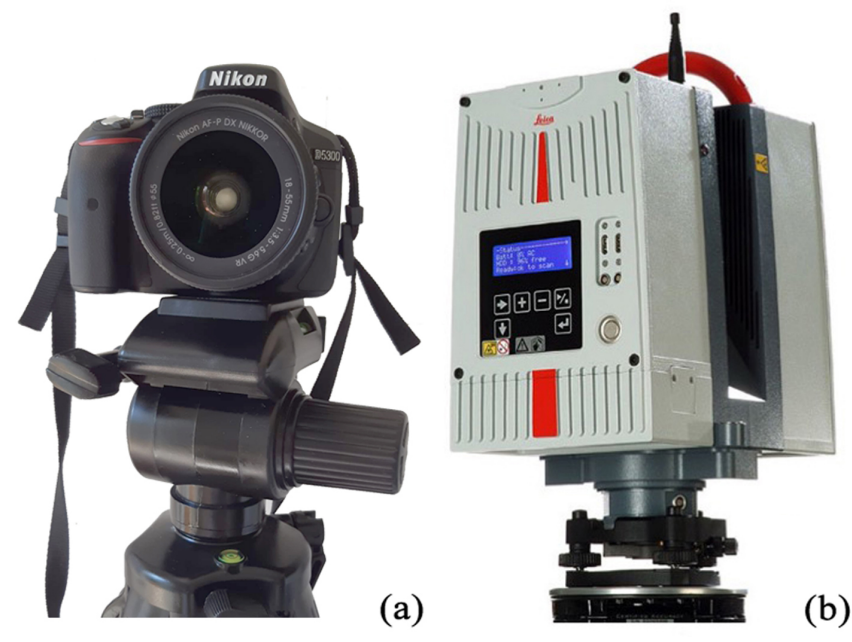

Figure 5. (a) The Nikon D5300 Camera. (b) The Leica HDS-6200 TLS.

high and ultra-high. A point cloud of ten to twenty million points was generated as a high resolution 3D model of the studied column to be used as input for the software JRC 3D Reconstructor ${ }^{\circledR}$ by Gexcel used finally to perform automatic filtering, meshing, and inspection procedure.

\subsubsection{Terrestrial Laser Scanner (TLS)}

As a general concept, TLS can be defined as an automated total station by which a laser beam is projected on the scene over a regular spaced grid using a servocontrolled mirror system (Fais et al., 2017). High rate repeated measurements of distances between the emitter of the laser beam and the reflecting surface of the illuminated objects are detected. Owing to the high level of automation of modern TLS used in architectural applications, different point clouds of millions of points per second are acquired all around the field of view of targeted objects (Davis et al., 2017). For every point of the acquired clouds the position is routinely measured in an arbitrary reference system (i.e. a point inside the sensor); while the radiometric parameter associated with TLS methodology is the reflectivity or reflectance that can be defined in first approximation as the ratio between the amount of energy reflected by the target and the amount of energy emitted by the laser diode.

In this work the TLS survey was planned and carried out with a Leica HDS-6200 phase shift TLS (Fig. 5b). In practice, after an examination of the target object, the survey was scheduled to select the best place to locate the station points. The survey was carried out on 4 station points inside the church evenly spaced around the studied column. We collected four points cloud (one for every station point) of some millions of points. Every station point cloud was rotated and translated with respect to each other; one of them was used as an intrinsic reference system (IRS). The clouds

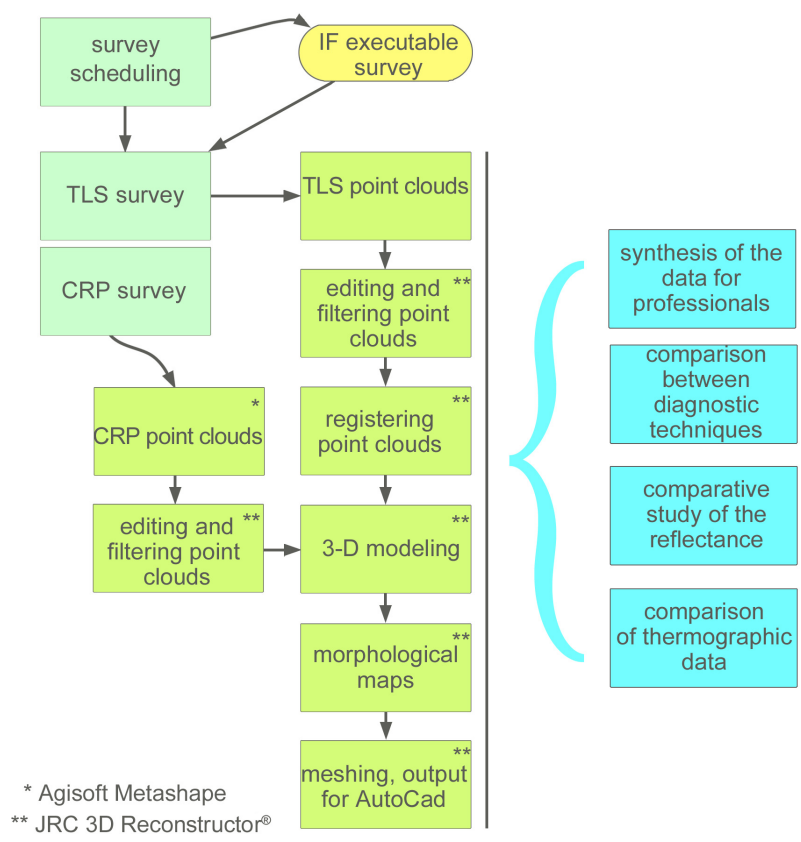

Figure 6. Flow chart of the TLS and CRP data acquisition and processing.

elaboration process of TLS data is performed with the aid of JRC 3D Reconstructor ${ }^{\circledR}$ by Gexcel and can be summarized as follows: point cloud input and format conversion, point cloud pre-processing and automated filtering or manual editing with the elimination of data out of tolerance and unusable points, cloud to cloud draft alignment and fine registration with bundle adjustment algorithms, cloud aggregation, 3D modelling and computation of morphological maps, output in a format suitable for input on AutoCAD ${ }^{\circledR}$ styled facilities (Fig. 6).

In particular, the point clouds were filtered, registered, and aggregated to form the model of the investigated building element. Moreover, in a second step we aggregated the data of the four previously described very dense point clouds to compute the 3D model of the column under study inside the ancient church of Saints Lorenzo and Pancratio.

\subsubsection{ND - Inspection Procedure}

At this stage of our procedure we applied the INSPECTION module of the JRC 3D Reconstructor ${ }^{\circledR}$ software by Gexcel to TLS and CRP aggregated point clouds to compute their geometrical anomalies as residuals compared to a best fitted cylindrical geometrical model adopting the corresponding high density $1 \mathrm{~mm}$ step mesh as reference (Fig. 7). The resulting highlighted surface anomalies precise at better that $1 \mathrm{~mm}$ are useful for comparison with other diagnostic techniques capable of investigating the internal structure of the Calcari di Cagliari column. In Fig. 7 below a view of the 3D model obtained after registration and aggregation of all the 
point clouds pertaining to this monument is represented. The radiometric information represented in colour scale denotes the geometrical anomalies pattern of the materials of the outer surface of the investigated column and are expressed in $\mathrm{mm}$.

\subsection{Ultrasonic test}

Starting from our knowledge of the textural characteristics of the building carbonate material and from the 3D reconstruction that was made with previous techniques (TLS and CRP), a 3D ultrasonic tomography was planned and carried out. The ultrasonic experimental investigation on the column was designed to determine the size and location of internal potential defects, and to detect cracks and karst cavities which hinder the transmission of the ultrasonic signal thus lowering the propagation velocity of the longitudinal wave.

Ultrasonic measurements were carried out by the transmission method according to the ISRM $(2007,2014)$ using a Portable Ultrasonic Non-Destructive Digital Indicating Tester (PUNDIT Lab Plus) device (Proceq, Schwerzenbach, Switzerland). The output signals were recorded by a portable oscilloscope (Fluke 96B) interfaced with a laptop. The transducers were piezoelectric with a frequency of $24 \mathrm{kHz}$. Considering that the surface of the column is quite rough and irregular due to natural causes, special care was used in choosing the best coupling between transducer and material. As coupling agent silicone snug sheets were used. This kind of coupling agent is especially advantageous in contributing to a better transmissibility of the ultrasonic signal, filling the irregularities at the interface while avoiding soiling the material and interfering with it. Moreover, in carbonate materials such as Pietra Forte, which is often affected by a different kind of porosity the use of visco-liquids such as epoxy or grease should be avoided because they can penetrate into the pores and induce variations in the longitudinal velocity propagation. The wave velocity between source and receiver transducer pair can be directly estimated by considering the source-receiver distance divided by the travel time. This velocity is the result of effects of the characteristics of the material along the ray path. In a complex situation, automated arrival picking techniques could not consistently detect first arrivals. We therefore carefully hand-picked arrivals of Pwaves for the tomography analysis. In order to obtain the spatial variation of the longitudinal wave velocity within the column, inversion of the velocity (i.e. tomography) is necessary. Travel time of the longitudinal elastic waves was measured along a great number of measurement paths between stations located on the perimeter of the investigated column (Fig. 8a), and each station was alternatively used as a transmitter and a receiver. For each travel time a minimum of five measurements were assessed. The acquisition scheme also assured a good ray coverage of the investigated material volume (Fig. 8b). Therefore, the column to be imaged was crisscrossed by a great number of discrete rays (1800). Each ray between stations was divided in small segments, each corresponding to a pixel element. The size of the pixels was determined by the number of source-receiver paths. The travel time of the longitudinal ultrasonic signals along the ray paths (source-receiver paths) was recorded together with the relative position and orientation of each ray in the investigated volume deduced from the TLS datasets. A tomographic inversion was applied to the data producing the $3 \mathrm{D}$ velocity model. The 3D representation of the distribution of the longitudinal wave velocity inside the investigated column was produced from the first break times by the SIRT tomographic inversion algorithm (Mendes, 2009). To obtain the initial velocity values for the iterative inversion, a methodology based on the use of the cross-correlation function (Fais and Casula, 2010) was applied.

The resulting 3D high resolution image is shown in Fig. 9. The colour scale in the figure varies from blue to red representing the great variation in longitudinal velocity inside the column.

\section{Results and discussion}

The integrated use of different NDTs such as TLS, CRP and ultrasonic tomography corroborated by analyses of the petrographic characteristics of the carbonate materials is of paramount importance to assess the state of conservation of the shallow and deeper zones of the stone materials that make up monuments. Knowledge of the carbonate material conditions and decay processes, as well as the mechanisms governing these processes depend on the intrinsic properties of the investigated material, such as mineral composition, texture, nature and distribution of porosity. Therefore, in this study, the workflow starts with an accurate examination of the petrographic characteristics of the carbonate materials by optical and SEM analysis of the thin sections (Fig. 3a, b) of the investigated carbonate materials used to assemble the column. The textural characteristics (e.g. secondary porosity due to dissolution phenomena) of the carbonate material are also reflected in the results of the macroscopic analysis of the column (Fig. 4). According to this visual inspection the building carbonate stone and the restoration materials suffer on account of the deterioration and decay at various locations due to the aging process and intrinsic characteristics of the carbonate stone material. At the macroscale secondary pores due to post-diagenetic dissolution processes typical of the Pietra Forte develop in karst cavities (Fig. 4). Texture and porosity of the material predispose the stone to different types of degradation and defects. Being a limestone in bioherma and biosroma facies, the Pietra Forte is characterized by multiple discontinuity surfaces due to the growth structures of fossil organisms and the interfaces between adjacent fossils or bioclasts. The above discontinuities represent preferential paths for the propagation of acid solutions, which in the building stone that makes up the inves- 


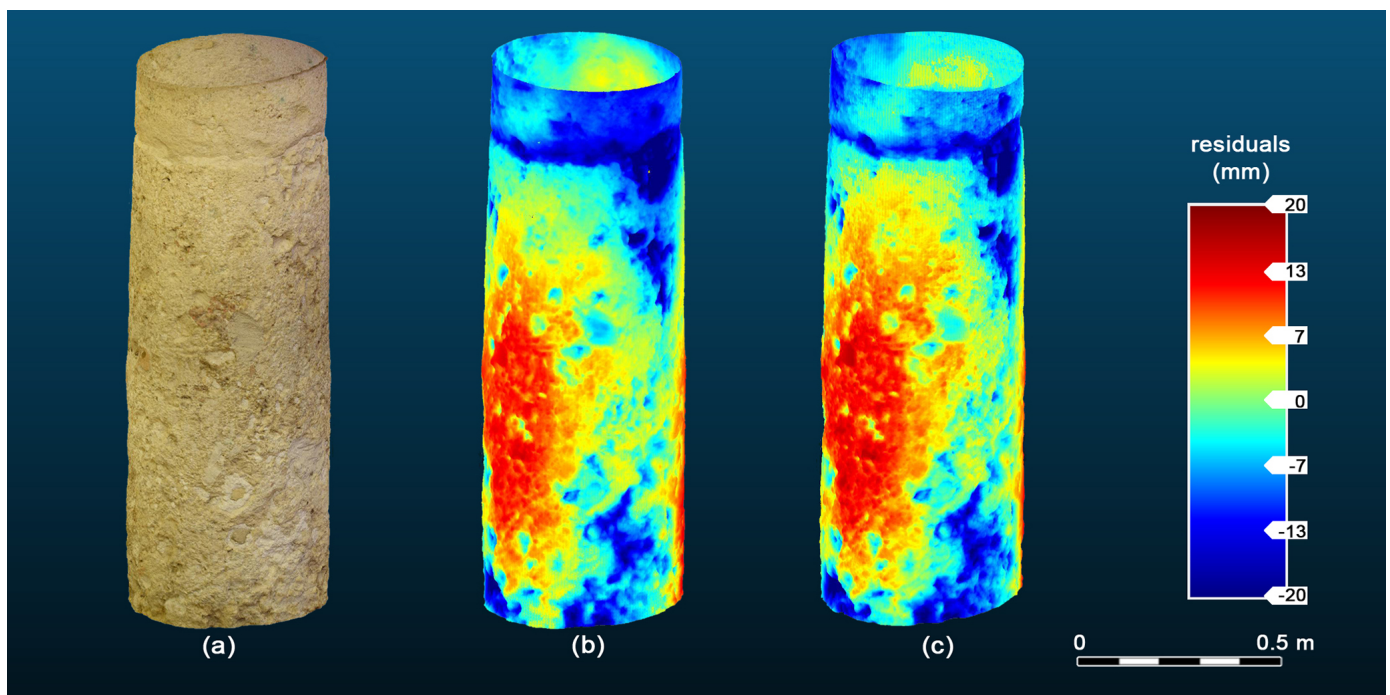

Figure 7. Detail of the body of the column object of this study. (a) 3D model derived from the synergistic application of CRP and TLS; (b) geometrical residuals (m) obtained by comparison of the CRP 3D model with the reference shape of a regular cylinder; (c) geometrical residuals ( $\mathrm{mm}$ ) obtained by comparison of the TLS 3D model with a regular cylinder. The comparison between the two techniques shows there are no significant differences between TLS and CRP. The differences are visible in the small details: in panel (c) the more prominent parts are more visible (graphic elaboration with JRC 3D Reconstructor ${ }^{\circledR}$ and CloudCompare, 2020).

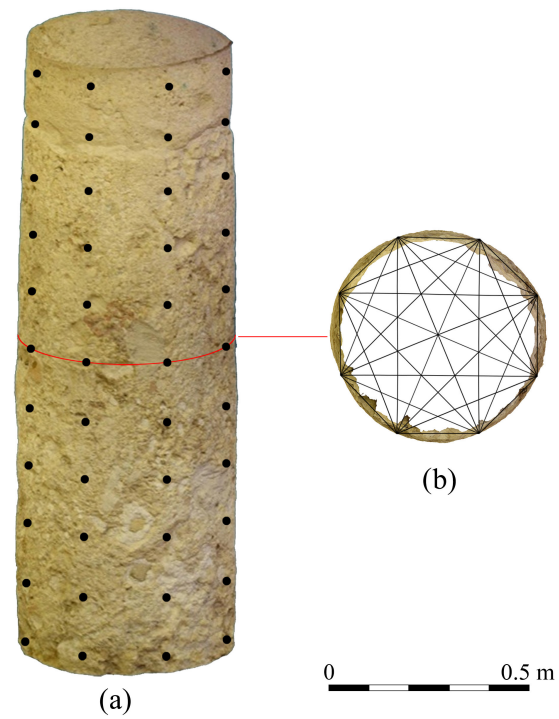

Figure 8. Ultrasonic tomography data acquisition: (a) transducer positions used for the tomographic reconstruction located on the 3D CRP-TLS model of the column; (b) 2D cross-section of the straight ray paths from the $3 \mathrm{D}$ acquisition scheme assuming a homogeneous material.

tigated structure, caused dissolution of the calcium carbonate and development of the secondary porosity favoring the anisotropy and increasing the number and size of the defects. These defects can be qualified and quantified both superficially and in depth using the geophysical methods applied in the present study. The next step of the diagnostic procedure was the study of the cylindrical shape of the previously described column that was 3D modelled by CRP and TLS techniques and analysed very precisely. The residuals of CRP and TLS 3D models, computed as the difference with respect to a meshed cylinder of a $1 \times 1 \mathrm{~mm}$ step fitted to the unified clouds and taken as a reference, are comparable in dimension and shape and vary in the range $\pm 20 \mathrm{~mm}$. In Fig. 7 the areas coloured in blue represent negative anomalies, while those in red represent the zones of the material characterized by positive anomalies compared to the regular cylindrical geometry adopted as a reference. The resulting CRP and TLS surface anomalies (Fig. 7) show the altered parts and defects of the shallow materials. Weathering and alteration zones, material detachments, heterogeneous distribution of macroporosity and variations in the texture of the stone material cause strong morphological irregularities on the shallow materials and are characterized by the transition between negative to positive values of the geometrical surface anomalies detected with TLS and CRP. This surface high data scattering (see red coloured area in Fig. 7) also reflects the internal conditions of the material as can be seen clearly in the 3D tomographic image (Fig. 9) where the velocity zones lower than $2000 \mathrm{~m} \mathrm{~s}^{-1}$ prevail and correspond to bad quality materials. Consequently, the flaws and damage patterns highlighted by the CRP and TLS models develop from the surface to the inner part of the column as seen from the 3D tomography model. The percentage of the defects in the carbonate building material comparing the 3D models from the CRP, TLS and ultrasonic tomography is about $60 \%$.

The ultrasonic longitudinal velocity presents a great variability between 300 and $5500 \mathrm{~m} \mathrm{~s}^{-1}$, denoting great variabil- 


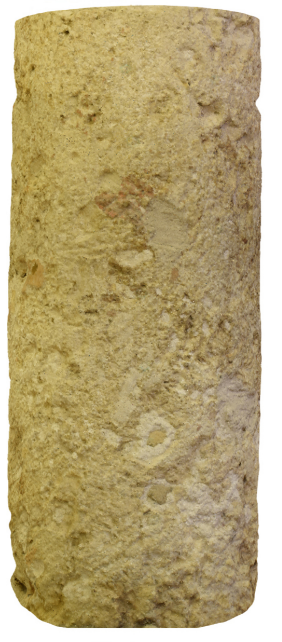

(a)
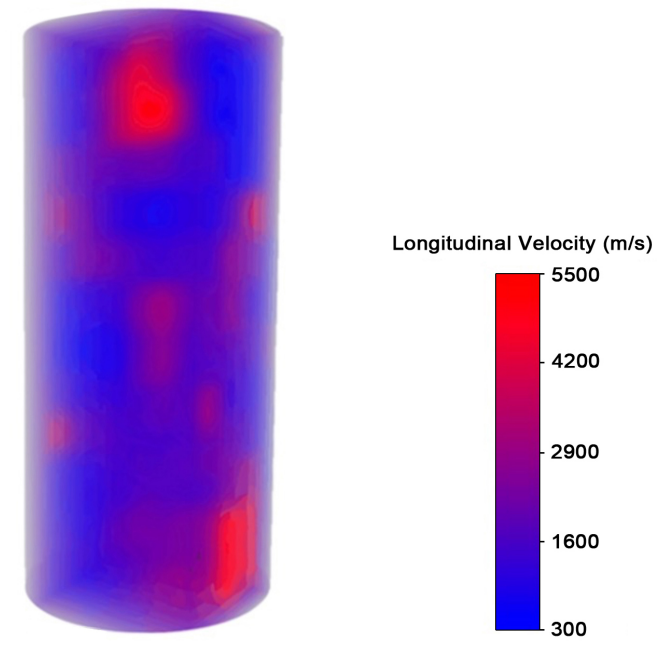

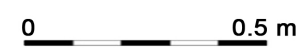

(b)

Figure 9. (a) Natural coloured textured 3D model of the column derived from CRP; (b) 3D ultrasonic tomography for the central column of the Saints Lorenzo and Pancratio church.

ity in the elastic characteristics of the carbonate building material. The elastic characteristics are generally poor due to the presence of macropores (e.g. small karst cavities) and discontinuities in the Pietra Forte. The pattern of the longitudinal velocity deduced by 3D tomography (Fig. 9) shows the intrinsic heterogeneity of the carbonate rock (Pietra Forte) in the shallow and inner part of the shaft of the investigated column. In sound carbonate Pietra Forte stone the longitudinal wave average velocity changes in the range of 5200$7000 \mathrm{~m} \mathrm{~s}^{-1}$ as seen from the laboratory measurements described in previous works (Cuccuru et al., 2014; Fais et al., 2018, 2019b). The macropores (e.g. small karst cavities) and the discontinuities within the column shaft caused a marked decrease in longitudinal velocity values as results from the 3D tomography (Fig. 9). In a compressive element such as the investigated column, the multitechniques diagnostic process assumes particular importance.

\section{Conclusions}

By combining the results of CRP, TLS and ultrasonic tomography investigations, an increase in the content of information about the detected anomalies and their relations with the shallow and inner conditions of the building materials is obtained. The three methods complement each other and thanks to the use of the multitechniques data volume in the diagnostic process the interpretation is freed from the limitations intrinsic in the single method. The integration of the different datasets proves to be more efficient if corroborated by the knowledge of the petrographic characteristics of the investigated carbonate material, especially the texture and the pore geometry. These characteristics affect the acoustic velocity, the TLS reflectivity and the morphological aspect (geometrical anomalies) of the shallow materials and thus the CRP images. The great precision of the position and spatial distribution of the geometric anomalies detected by CRP and TLS represented an efficient dataset for the best design and acquisition of the 3D ultrasonic tomography. The latter was effective in providing an accurate image of the longitudinal velocity distribution inside the column enhancing the analysis and allowing a fine characterization of the materials in terms of elastic properties. The combination of different techniques and disciplines can be a solution to the non-invasive diagnostic process on the conservation state of a monument allowing to choose the optimal restoration and to check its efficiency in time.

Data availability. Data are available upon request by conctacting the corresponding author.

Author contributions. SF and GC conceived the new integrated methodology; FC contributed to the analysis of the materials; SF performed ultrasonic test with the collaboration of PL; SF and FC performed the integrated ultrasonic and petrographic analysis and its interpretation; FC and GC processed photogrammetric data; GC and MGB processed and interpreted TLS data; All the authors analysed the results, contributed to the manuscript drafting and to prepare the figures. All authors reviewed the manuscript. 
Competing interests. The authors declare that they have no conflict of interest.

Special issue statement. This article is part of the special issue "European Geosciences Union General Assembly 2020, EGU Division Energy, Resources \& Environment (ERE)"'. It is a result of the EGU General Assembly 2020, 4-8 May 2020.

Acknowledgements. The authors would like to thank Archidiocesi di Cagliari (ITALY) and Mons. Mario Ledda for their kind permission to work on the Saints Lorenzo and Pancratio Church.

Financial support. This work was partially supported by FIR (Fondi integrativi per la Ricerca) funded by the University of Cagliari (Italy) and RAS/FBS (grant number: F71/17000190002) grants for funding.

Review statement. This paper was edited by Viktor J. Bruckman and reviewed by two anonymous referees.

\section{References}

Adamopoulos, E. and Rinaudo, F.: 3D Interpretation and Fusion of Multidisciplinary Data for Heritage Science: A Review, Int. Arch. Photogramm. Remote Sens. Spatial Inf. Sci., XLII-2/W15, 17-24, https://doi.org/10.5194/isprs-archivesXLII-2-W15-17-2019, 2019.

Anselmetti, F. S. and Eberli, G. P.: Sonic Velocity in Carbonate Sediments and Rocks, in: Carbonate Seismology, edited by: Palaz, I. and Marfurt, K. J., Society of Exploration Geophysicists, Tulsa, Oklahoma, USA, 53-74, 1997.

Bianchi, M. G., Casula, G., Cuccuru, F., Fais, S., Ligas, P., and Ferrara, C.: Three-dimensional imaging from laser scanner, photogrammetric and acoustic non-destructive techniques in the characterization of stone building materials, Adv. Geosci., 45, 57-62, https://doi.org/10.5194/adgeo-45-57-2018, 2018.

Blistan, P., Jacko, S., Kovanič, L., Kondela, J., Pukanská, K., and Bartoš, K.: TLS and SfM Approach for Bulk Density Determination of Excavated Heterogeneous Raw Materials, Minerals, 10, 174, https://doi.org/10.3390/min10020174, 2020.

Casula, G., Fais, S., and Ligas, P.: An experimental application of a 3D terrestrial laser scanner and acoustic techniques in assessing the quality of the stones used in monumental structures, IJMMP, 4, 45-56, https://doi.org/10.1504/IJMMP.2009.028432, 2009.

Cherchi, A. Appunti biostratigrafici sul Miocene della Sardegna (Italia), (Sardegna), Mem. B.R.G.M., 78, 433-445, 1974.

Christaras, B., Cuccuru, F., Fais, S., and Papanikolaou, H.: Application of non destructive ultrasonic techniques for the analysis of the conservation status of building materials in monumental structures, in: Engineering Geology for Society and Territory Volume 8, 139-143, Springer, Basel, Switzerland, 2015.
CloudCompare: CloudCompare (version 2.11 Beta) [GPL software], available at: http://www.cloudcompare.org/, last access: 10 June 2020.

Coroneo, R., Naitza, S., and Tore, D.: Architettura romanica dalla metà del Mille al primo'300, Ilisso, Nuoro, Italy, 1993.

Cuccuru, F., Fais, S., and Ligas, P.: Dynamic elastic characterization of carbonate rocks used as building materials in the historical city centre of Cagliari (Italy), Q. J. Eng. Geol. Hydroge., 47, 259266, https://doi.org/10.1144/qjegh2013-061, 2014.

Davis, A., Belton, D., Helmholz, P., Bourke, P., and McDonald, J.: Pilbara rock art: laser scanning, photogrammetry and 3D photographic reconstruction as heritage management tools, Herit. Sci., 5, 25, https://doi.org/10.1186/s40494-017-0140-7, 2017.

Dunham, R. J.: Classification of carbonate rocks according to depositional textures, AAPG memoir, 1 (Classification of carbonate rocks), 108-121, 1962.

Eberli, G. P., Baechle, G. T., Anselmetti, F. S., and Incze, M. L.: Factors Controlling Elastic Properties in Carbonate Sediments and Rocks, Lead. Edge, 22, 654-660, 2003.

Fais, S. and Casula, G.: Application of acoustic techniques in the evaluation of heterogeneous building materials, NDT \& E International, 43, 62-69, https://doi.org/10.1016/j.ndteint.2009.10.004, 2010.

Fais, S., Ligas, P., Cuccuru, F., Maggio, E., Plaisant, A., Pettinau, A., Casula, G., and Bianchi, M. G.: Detailed Petrophysical and Geophysical Characterization of Core Samples from the Potential Caprock-reservoir System in the Sulcis Coal Basin (Southwestern Sardinia - Italy), Enrgy. Proced., 76, 503-511, https://doi.org/10.1016/j.egypro.2015.07.899, 2015.

Fais, S., Cuccuru, F., Ligas, P., Casula, G., and Bianchi, M. G.: Integrated ultrasonic, laser scanning and petrographical characterisation of carbonate building materials on an architectural structure of a historic building, B. Eng. Geol. Environ., 76, 71-84, https://doi.org/10.1007/s10064-015-0815-9, 2017.

Fais, S., Casula, G., Cuccuru, F., Ligas, P., and Bianchi, M. G.: An innovative methodology for the non-destructive diagnosis of architectural elements of ancient historical buildings, Sci. Rep., 8, 4334, https://doi.org/10.1038/s41598-018-22601-5, 2018.

Fais, S., Casula, G., Cuccuru, F., Ligas, P., Bianchi, M. G., Plaisant, A., and Pettinau, A.: A Contribution to the Geological Characterization of a Potential Caprock-Reservoir System in the Sulcis Coal Basin (South-Western Sardinia), Energies, 12, 4524, https://doi.org/10.3390/en12234524, 2019a.

Fais, S., Cuccuru, F., Casula, G., Bianchi, M. G., and Ligas, P.: Characterization of Rock Samples by A High-Resolution Multi-Technique Non-Invasive Approach, Minerals, 9, 664, https://doi.org/10.3390/min9110664, 2019b.

Gandolfi, R. and Porcu, A.: Contributo alla conoscenza delle microfacies mioceniche delle colline di Cagliari (Sardegna), Riv. Ital. Paleont., 73, 313-348, 1967.

ISRM: The complete ISRM suggested methods for rock characterization, testing and monitoring: 1974-2006, in: Suggested Methods Prepared by the Commission on Testing Methods, edited by: Ulusay, R. and Hodson, J. A., International Society for Rock Mechanics, Compilation Arranged by the ISRM Turkish National Group Ankara, Turkey, p. 628, 2007.

ISRM: Upgraded ISRM Suggested Method for Determining Sound Velocity by Ultrasonic Pulse Transmission Technique, in: The ISRM Suggested Methods for Rock Characterization, edited by: 
Ulusay, R., Testing and Monitoring: 2007-2014, Cham Heidelberg New York Dordrecht London, 95-99, 2014.

Mendes, M.: A hybrid fast algorithm for first arrivals tomography, Geophys. Prospect., 57, 803-809, https://doi.org/10.1111/j.1365-2478.2008.00755.x, 2009.

Montuori, A., Luzi, G., Stramondo, S., Casula, G., Bignami, C., Bonali, E., Bianchi, M. G., and Crosetto, M.: Combined use of ground-based systems for Cultural Heritage conservation monitoring, in: 2014 IEEE Geoscience and Remote Sensing Symposium, IEEE, 13-18 July 2014, Quebec City, QC., Canada, 40864089, 2014.

Montuori, A., Costanzo, A., Gaudiosi, I., Vecchio, A., Apa, M. I. P., Gervasi, A., Falcone, S., La Piana, C., Minasi, M., Stramondo, S., Buongiorno, M. F., Doumaz, F., Musacchio, M., Casula, G., Caserta, A., Speranza, F., Bianchi, M. G., Guerra, I., Porco, G., Compagnone, L., Cuomo, M., and De, M.: The MASSIMO system for the safeguarding of historic buildings in a seismic area: operationally-oriented platforms, Eur. J. Remote Sens., 49, $397-$ 415, https://doi.org/10.5721/EuJRS20164922, 2016.

Soete, J., Kleipool, L. M., Claes, H., Claes, S., Hamaekers, H., Kele, S., Ozkul, M., Foubert, A., Reijmer, J. J. G., and Swennen, R.: Acoustic properties in travertines and their relation to porosity and pore types, Mar. Petrol. Geol., 59, 320-335, https://doi.org/10.1016/j.marpetgeo.2014.09.004, 2015.
Vasanelli, E., Colangiuli, D., Calia, A., Sileo, M., and Aiello, M. A.: Ultrasonic pulse velocity for the evaluation of physical and mechanical properties of a highly porous building limestone, Ultrasonics, 60, 33-40, https://doi.org/10.1016/j.ultras.2015.02.010, 2015.

Wang, Y. and Li, X.: Experimental study on cracking damage characteristics of a soil and rock mixture by UPV testing, B. Eng. Geol. Environ., 74, 775-788, 2015.

Weger, R. J., Baechle, G. T., Masaferro, J. L., and Eberli, G. P.: Effects of porestructure on sonic velocity in carbonates, in: SEG Technical Program Expanded Abstracts 2004, vol. 23, 1774 1777, Society of Exploration Geophysicists, Houston, Texas, USA, 2004.

Westoby, M. J., Brasington, J., Glasser, N. F., Hambrey, M. J., and Reynolds, J. M.: "Structure-from-Motion" photogrammetry: A low-cost, effective tool for geoscience applications, Geomorphology, 179, 300-314, https://doi.org/10.1016/j.geomorph.2012.08.021, 2012. 